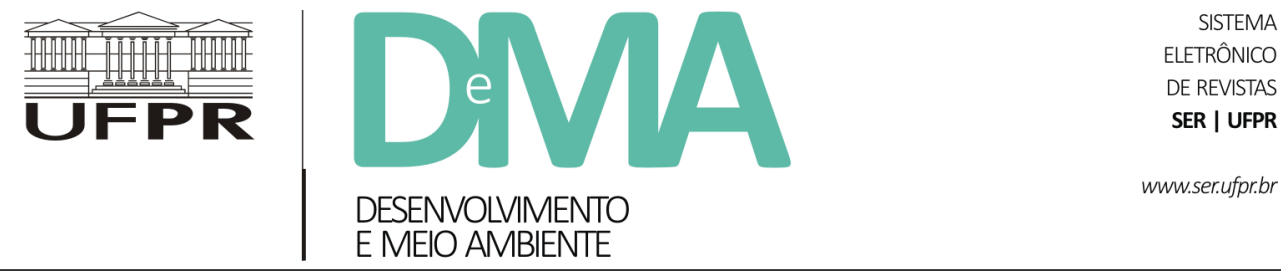

\title{
Ética e técnica em Jonas e Levinas: diferenciações e aproximações
}

\section{Ethics and Technique in Jonas and Levinas: Differences and Approaches}

\author{
Ozanan Vicente CARRARA ${ }^{1 *}$ \\ ${ }^{1}$ Universidade Federal Fluminense (UFF), Volta Redonda, RJ, Brasil. \\ *E-mail de contato: ozanan.vc@uol.com.br
}

Artigo recebido em 23 de março de 2016, versão final aceita em 22 de junho de 2017.

\begin{abstract}
RESUMO: O presente artigo aborda, a partir de alguns textos e passagens dos filósofos Jonas e Levinas, sobretudo Technologie et Responsabilité, do primeiro, e Heidegger, Gagarine et nous, do segundo, a questão da relação entre ética e técnica. Jonas funda a ética em uma ontologia, sendo a técnica, em sua concepção, parte constitutiva da natureza humana, aquilo mesmo que instala o homem na humanidade, ligando-a o autor à preservação e à continuidade da existência em todos os níveis: o da existência humana e o da existência não humana. Para Levinas, a ética dispensa uma ontologia que a prepare, sendo ela mesma a filosofia primeira. Sendo sua ética um esforço de buscar o humano em toda sua profundidade, concebe a técnica como aquilo que permite perceber o humano em toda sua intensidade, libertando-o do mundo e do contexto, abrindo a possibilidade de uma subjetividade que é habitação, acolhimento e aceitação de outrem. Após caracterizar o pensamento da ética em ambos os autores e de situar a técnica e a tecnologia dentro de seus projetos éticos, o artigo busca os elementos comuns nos dois pensadores que ajudam a pensar a ética ambiental e suas questões fundamentais, como as da humanidade e animalidade, encontrando um elemento comum na noção de responsabilidade tão fundamental às formas de os dois autores pensarem a ética. É pela responsabilidade que éticas tão diferentes conservam uma abertura à alteridade, seja na forma das futuras gerações (Jonas), seja ao outro, na figura do Rosto (Levinas), que, alargada, pode incluir também os seres não humanos.
\end{abstract}

Palavras-chave: ética; técnica; Jonas; Levinas; ética ambiental.

ABSTRACT: This article presents the thinking of the philosophers Jonas and Levinas, through some texts and passages, specially Technologie et Responsabilité from the first and Heidegger, Gagarine et nous from the latter, about the relation between ethics and technique. Jonas founds his ethics in an Ontology, in which technique is a constitutive part of the human nature. Technique installs human beings in humanity, fact that allows the author to relate it to preservation and continuity of existence in all levels: human and nonhuman. As to Levinas, ethics is the first philosophy and exempts an ontology that prepares it, while technique is seen as that which allows 
seeing human in all its intensity, leaving it free from the world and from a context, opening thus a possibility of a subjectivity that is welcoming and acceptance of alterity. After characterizing ethics in both authors and situating technique and technology within their philosophical projects, this article seeks for common elements in both thinkers. Such a correlation helps to think an environmental ethics and its fundamental questions such as humanity and animality, finding a common element in the notion of responsibility, essential to both thoughts of ethics. It is through responsibility that such different thoughts keep an openness to alterity, whether it is the alterity of future generations (Jonas) or the alterity of the other man (Levinas), the figure of which is the notion of face (visage) that, when enlarged, can also include natural beings.

Keywords: ethics; technique; Jonas; Levinas; environmental ethics.

\section{1. Ética e técnica em Jonas}

Nem Jonas nem Levinas são pensadores da ética ambiental e tampouco são filósofos da técnica rigorosamente falando, mas seus textos têm muito a dizer sobre isso que se tornou essencial no mundo contemporâneo e é o eixo central da ética ambiental produzida no continente europeu. Que lugar, então, a técnica ocupa em um pensamento voltado para a construção de uma ética para a civilização tecnológica (Jonas) e em uma ética que é vista como a filosofia primeira e dispensa uma ontologia que a prepare (Levinas)? Se Heidegger ficou conhecido por certa tendência à tecnofobia, como se posicionam Jonas e Levinas, ambos fortemente influenciados pelo filósofo alemão? Como podemos situar as duas filosofias quanto a uma visão mais positiva (tecnofilia) ou mais negativa (tecnofobia) da técnica? Como as duas éticas podem contribuir para responder aos desafios trazidos pela ética ambiental? Como os dois autores entendem as noções fundamentais da ética ambiental, quais sejam, a humanidade e a animalidade? Tais são as questões de fundo do texto presente!

Jonas não escreveu nenhum texto específico sobre a técnica, mas o tema serve de pano de fundo para quase todas as suas reflexões. Três de suas obras mais importantes abordam a questão da técnica. São elas: Essais philosophiques: Du Credo ancien à l'homme technologique, Le Principe Responsabilité e Technique, Medicin et Ethique. Interessam-nos, para nosso propósito, alguns elementos dos dois primeiros textos. Jonas se mostra convencido, seguindo a reflexão de Heidegger, de que a tecnologia é a marca característica da civilização contemporânea e é nela o tipo dominante de conhecimento e prática. Não é a técnica em si que lhe interessa, mas antes suas consequências e efeitos, o que dirige sua reflexão para a dimensão ética da técnica. $O$ fato de ser um crítico voraz das consequências da técnica e de suas ameaças tanto ao ser humano como à natureza lhe rendeu a fama de tecnofóbico, embora ele veja nela também aspectos positivos, sobretudo quando fala das biotecnologias médicas.

Em seu Essais philosophiques (1974), Jonas descreve os desafios que, a seu ver, tornavam obrigatória a elaboração de uma nova ética, projeto que ele levará adiante em seu $O$ Princípio Responsabilidade (1979). No primeiro texto, Jonas começa pela crítica às éticas tradicionais que partiam de algumas premissas como um conceito determinado de natureza humana e da natureza das coisas que condicionam o humano, base a partir da qual o bem humano é facilmente determinado; e da ideia de que nosso campo de ação moral e de responsabilidade é 
delimitado. Tais premissas não valem mais diante dos novos desafios colocados à humanidade pela civilização tecnológica que acabou por conferir ao homem um poder de grandes proporções sobre a natureza, obrigando a ética a responder a este desafio. É preciso, então, tomar consciência de como esta tecnologia afeta a natureza de nosso agir e estudar as diferenças entre a tecnologia moderna e a tecnologia anterior e como elas permitiram ao homem intervir tão intensamente na natureza. Jonas parte da constatação de uma conivência implícita entre a ideia de civilização e a violação à natureza que se abriga sob a cidade e suas leis tal como elas foram sendo construídas ao longo da história humana. Afirmando-se através do domínio da natureza, o homem acabou por submeter tudo à sua vontade e às suas necessidades, dando-se poderes ilimitados e capazes de intervir sobre a natureza de maneira cada vez mais audaciosa. Se as tecnologias anteriores lhe davam apenas um poder de intervenção que não tocava no equilíbrio da natureza, agora as novas tecnologias lhe dão poderes que ultrapassam em muito os da cidade de outrora (Jonas, 2013, p. 27-28).

Nas éticas antigas, a natureza nunca foi objeto de preocupação da ética e da responsabilidade, uma vez que está submetida a uma lei que a entrega à própria evolução. Eram os homens na cidade que se submetiam às leis morais que regulavam as relações inter-humanas. No contexto das éticas tradicionais, toda intervenção no mundo não humano era desprovida de valor moral ou moralmente neutra, no que diz respeito tanto ao objeto quanto ao sujeito da ação moral. A ação moral dizia respeito unicamente às relações de homem a homem. E a essência do homem era compreendida como sendo permanente, não estando nunca sujeita à ação transformadora da técnica. O bem e o mal de uma ação estavam circunscritos à proximidade imediata do agente moral, no que dizia respeito tanto ao tempo como ao espaço. O homem virtuoso era aquele que se portava com sabedoria, cultivando suas próprias inclinações e tendências das quais a natureza o proveu. Todas as prescrições morais se limitavam ao quadro restrito de sua ação imediata: ama teu próximo como a ti mesmo, faze aos outros o que esperas que te façam a ti, educa teu filho na verdade, desenvolve todas as potencialidades do teu ser, submete teus interesses ao bem comum, trata o outro como fim e jamais como meio, etc. Em tais máximas, tanto o agente moral como o outro partilham um presente comum. O futuro não dizia respeito à ação moral, excluindo dela as gerações vindouras (Jonas, 2013, p. 29-30).

Também o saber antigo se enquadrava nestes mesmos limites da ação moral, sendo acessível ao homem comum que nunca alcançava o saber do expert ou do sábio. Immanuel Kant mostra que a moral não é questão de saber ou de inteligência privilegiada de alguns, mas o resultado do exercício da razão por parte de qualquer indivíduo racional que pode encontrar por si mesmo o agir segundo a lei moral que se baseia, afinal, nos componentes invariáveis e universais da razão humana. No entanto, diz Jonas, mesmo essa ação se limitava ao aqui e agora. Em outros termos, não existia um saber preditivo, já que o bem humano era sempre o mesmo por toda parte e em todas as épocas, além de sua realização ou transgressão dizerem respeito somente ao presente.

Entretanto, a tecnologia moderna mudou tudo isso radicalmente, trazendo ações com alcance, objetos e consequências jamais pensados pelas éticas tradicionais cujas prescrições de justiça, caridade e honestidade não perderam a validade, mas se 
mostram insuficientes ou incapazes de atingir a ação coletiva em que agente, ato e efeito não são mais aqueles da proximidade, dotando a responsabilidade humana de uma dimensão jamais imaginada. Jonas toma como exemplo a vulnerabilidade em que a natureza se encontra diante das intervenções tecnológicas do homem. As novas ciências, sobretudo a da ecologia, modificam o conceito que temos de nós mesmos como fator causal do que se passa no universo. A ação humana acha-se agora capaz de atingir toda a biosfera. A ética se encontra agora diante da natureza como seu novo objeto, levantando a questão sobre que tipo de obrigação temos para com ela para além de um mero utilitarismo. É todo o gênero humano que se encontra ameaçado pela ação humana, especialmente as gerações vindouras, ou ainda é a sobrevivência da própria espécie humana que está em jogo. Fala-se de um encadeamento de fatores causais que se acumulam e que modificam a situação do agir moral, uma vez que as consequências desse agir não podem ser previstas pela intenção inicial. Há novos elementos que devem ser objeto da intenção da vontade da ação individual para que ela seja moralmente válida, diz Jonas (Jonas, 2013, p. 33-34).

Impõe-se também a necessidade de um novo saber, proporcional à nova escala causal de nossas ações morais, isto é, um saber preditivo à altura do saber tecnológico atual. Não há desculpas para a ignorância, mas um dever de saber e conhecer as consequências dos poderes tecnológicos de que dispomos, amparados numa ética que dê conta dessa situação global da vida humana e da sobrevivência da espécie humana no futuro longínquo. Destarte, impõe-se um novo conceito de direitos e de deveres que não se encontra nas éticas anteriores. É preciso responder à questão do tipo de obrigação que temos para com a natureza não humana, para com a biosfera como um todo e em suas partes, submetidas ao nosso poder, e descobrir a dignidade própria que lhes é pertinente. A ética doravante tem de se preocupar não somente com o bem humano, mas também com o bem das coisas e seres não humanos, reconhecendo-os também como fins em si mesmos, dignidade da qual eles foram desprovidos pelas éticas anteriores. Para Jonas, isso implica não somente pensar uma nova doutrina do fazer (ética), mas também uma nova doutrina do ser (ontologia) que sustente essa ética.

Ademais, a técnica dos antigos se via como um meio adequado aos fins humanos que ela se propunha atingir. Na cultura tecnológica contemporânea, a técnica deixou de ser um acessório humano para ganhar um lugar central dentro do projeto humano, considerando que a expansão do poder humano sobre tudo se faz acompanhar de "uma contração de sua concepção de si e de seu ser" (Jonas, 2013, p. 35). A contemporaneidade coloca a responsabilidade humana diante de um futuro indeterminado, não sendo mais a ação individual que importa, mas a ação coletiva. Novos imperativos éticos se fazem necessários, assim como essa mudança na ação humana obriga também uma mudança na política. Não há mais fronteira entre a cidade e a natureza, pois o mundo dos homens entra na esfera da natureza e "usurpa seu lugar". Apagam-se as diferenças entre o artificial e o natural e um se mistura ao outro. A ética se vê diante de uma obrigação prática em relação à posteridade, num futuro distante cuja existência agora se vê condicionada às nossas ações presentes, componente este ausente nas éticas tradicionais. A continuidade do homem no mundo não é mais um dado indubitável, tornando-se ela mesma um objeto de obrigação. 
Jonas então formula um novo imperativo ético, traduzindo para o presente o imperativo categórico da ética kantiana. Se, para Kant, importavam a razão e sua coerência consigo mesma, Jonas diz que a moral, nesse caso, se funda na lógica e em sua compatibilidade ou incompatibilidade lógica interna. No entanto, a sobrevivência da humanidade nas gerações futuras ou o sacrifício que as atuais gerações precisam se impor em nome do bem das gerações futuras não se resume a uma questão de lógica ou de coerência lógica. Há um imperativo que se torna necessário, que é o de que a humanidade continue a existir, um imperativo que não é interno à vontade, como em Kant, mas que vem do exterior. Trata-se, então, de um imperativo cujo fundamento é metafísico e que pode ser enunciado da seguinte maneira: "Age de tal maneira que os efeitos de tua ação sejam compatíveis com a permanência de uma vida humana autêntica" ou, formulado de maneira negativa; "Age de tal maneira que os efeitos de tua ação não sejam destruidores da possibilidade futura de uma tal vida" (Jonas, 2013, p. 37).

Jonas ressalta que não há, em seu novo imperativo, nenhum tipo de contradição racional, pois “eu posso querer o bem presente ao preço do sacrifício do bem futuro". Logo, esse novo imperativo se dirige à política pública e não à conduta privada de cada cidadão. Na ética kantiana, eu me permito fazer moralmente aquilo que cada indivíduo racional também pode se permitir fazer, estando minha ação individual obrigada a se conformar ao que ditaria uma lei universal. Para Jonas, as consequências da ação individual não são consideradas no imperativo kantiano, nem seu princípio é um princípio de responsabilidade universal. A coerência que seu novo princípio exige não é "a do ato consigo mesmo, mas aquela dos efeitos que se seguem quanto à perpe- tuação de um agir humano no tempo futuro", nem sua universalização é hipotética como a de "um eu individual que se transfere a um todo imaginário, sem relação causal ao primeiro (se todos agissem dessa maneira); ao contrário, as ações sujeitas ao novo imperativo - ações do todo coletivo - têm sua referência universal no alcance efetivo de sua eficácia (...)" (Jonas, 2013, p. 38). Se o imperativo kantiano "extrapola numa ordem sempre presente de compatibilidade abstrata, nosso imperativo extrapola num futuro real previsível que faz com que nossa responsabilidade seja sem limite de duração" (Jonas, 2013, p. 38).

Assim, essa nova ordem da ação humana exige uma nova ética de prevenção e uma responsabilidade à sua altura. E essa nova tecnologia não afeta somente o domínio não humano, mas o próprio homem é afetado como objeto da tecnologia, uma vez que ela atinge a definição mesma da condição humana. O exemplo que Jonas dá se refere às contribuições dos progressos da biologia celular que permitem prolongar a existência, agindo contra o processo bioquímico do envelhecimento, de tal modo que "a morte não aparece mais como uma necessidade pertencendo à natureza da vida, mas como um disfuncionamento orgânico evitável que pode ser tratado" (Jonas, 2013, p. 39). Um segundo exemplo é o controle do comportamento ou o controle mental por meios químicos ou por ação elétrica sobre o cérebro, o que, ainda que seja para fins aceitáveis, pode trazer tanto efeitos benéficos quanto perigos potenciais. Uma coisa é usar tais técnicas para o alívio da dor e do sofrimento num doente, e outra coisa é fazer uma aplicação social dessas mesmas técnicas com o fim de mudar um comportamento individual indesejável, como o de um adolescente violento, por exemplo. No último 
caso, estão implicadas, evidentemente, questões de direitos humanos e da dignidade da pessoa humana que se deve tomar em conta. Jonas cita ainda o exemplo de uma empresa que pode se interessar por essas técnicas para obter melhores rendimentos de seus empregados. Em ambos os casos, coloca-se em questão a responsabilidade da qual os indivíduos devem ser capazes e para a qual devem ser educados. Jonas alude ainda a um terceiro exemplo: o do controle genético do homem futuro com vistas a melhorar a espécie humana. A questão de fundo é sempre a mesma: temos o direito moral de fazê-lo?

Toda a extensão e o alcance ilimitados do poder que a técnica trouxe ao homem contemporâneo exigem uma reflexão da ética e, como Jonas sugere, também uma atitude de humildade que não significa pequenez, mas uma humildade que pede prudência e equilíbrio no uso das enormes possibilidades que a tecnologia oferece, principalmente quando se ignoram as consequências e os efeitos a longo prazo de algumas delas.

Ainda atenta Jonas para o fato de que o mesmo movimento que nos concedeu poderes que devem ser regidos por normas, isto é, a ciência moderna, esse mesmo movimento corroeu pela base a ideia mesma de norma como tal. Embora a ciência moderna rejeite a ideia de norma, ela não pode, no entanto, rejeitar o sentimento que subjaz à ideia de norma. Como consequência disso, a natureza se apresenta como moralmente neutra ou desprovida de valor, já que a modernidade trouxe consigo não somente a dessacralização da natureza, mas concomitantemente a dessacralização da ética. Jonas sugere que o medo diante das consequências dos poderes extremos que alcançamos seja o melhor substituto da virtude e da sabedoria autênticas, capaz de nos fazer buscar e respeitar princípios éticos norteadores de nossas ações. É o que ele denomina "heurística do medo"! A religião não pode mais fornecer um fundamento seguro para a ética, como nas éticas do passado, devendo ela se fundar doravante na razão.

Que tipo de revolução a técnica opera na sociedade contemporânea? Examinando a Revolução Científica do século XVII, Jonas compara o conceito de revolução ao de evolução, sendo a evolução um processo lento e que ocorre de maneira imperceptível, enquanto a revolução é uma mudança mais radical, brusca e às vezes violenta, de alcance global, que afeta o pensamento, o comportamento e o ambiente humanos. O homem é tanto agente quanto objeto da revolução que termina por mudar radicalmente suas condições de vida. Enquanto alguns filósofos da técnica localizam seu início no século XVI e outros somente no século XIX, Jonas o situa no século XVII, embora seu auge tenha sido atingido primeiro na Revolução Francesa, depois na Revolução Industrial do século XIX e na Primeira Guerra Mundial, acontecimentos que marcam as diferentes etapas da Revolução Científica à qual se segue a técnica. Ela foi primeiro uma revolução intelectual e, somente num segundo momento, prática. Para Jonas, duas obras são fundamentais para esse novo pensamento científico, publicadas em 1543, quais sejam, Sur de révolutions des orbes celestes, de Nicolau Copérnico, e La Fabrique du corps humain, de André Vésale. Tais obras apontam para dois aspectos complementares do pensamento científico, quais sejam, o recurso à abstração matemática para explicar o universo e a observação de mecanismos vivos mais e mais microscópicos. Essa nova visão de mundo afeta de maneira decisiva e radical a existência do ser humano e sua relação com o meio ambiente. Mas qual a metafísica que está por trás dessa Revolução Científica? 
Para Jonas, a palavra que caracteriza as obras de Galileu e Bacon que se seguiram à Revolução Científica é novidade: novas terras, novos povos, novas abordagens do passado que modificam o pensamento. Na sabedoria antiga, o conhecimento se fundava nos textos antigos, sobretudo de Aristóteles, e a tradição que eles encerravam se tornava o critério máximo da verdade. A ciência moderna introduz novos conceitos de matéria e de natureza, sendo a matéria um ser homogêneo, quantificável e regido pelas leis da mecânica. A natureza é então governada pelas causas eficientes que a determinam, tornam-na manipulável e lhe retiram todo valor intrínseco. No entanto, Jonas está convencido de que nenhuma descoberta anulou a presença da causa final na natureza. Ele sustenta a diferença entre a liberdade e a causalidade mecânica e afirma que elas não são incompatíveis. Isso lhe permite ampliar o conceito de natureza, vendo-a como um encadeamento de causas eficientes e de causas finais. As causas eficientes ajudam na investigação dos detalhes e nas simplificações que exigem o método experimental. No entanto, a teleologia jonasiana não tem como objetivo explicar a natureza em termos de fins, mas sim interpretá-la. Segundo Pinsart, a redução ontológica e epistemológica que opera a ciência moderna funda-se numa posição agnóstica que dispensa todo esforço de compreensão. A experiência interna do ser humano não é considerada fonte de conhecimento para as ciências naturais que terminam por proibir a investigação das causas finais (Pinsart, 2003, p. 190).

Ainda segundo Pinsart, outras características fundamentais da ciência moderna são, além de sua inseparabilidade da técnica, o papel da análise na aquisição de conhecimentos e o da experimentação.
A análise permite reduzir um fenômeno complexo, tornando possível retomar o desenvolvimento complementar da síntese, isto é, da reconstituição, modificação ou criação de um objeto complexo a partir dos elementos que o constituem. A experimentação, por sua vez, permite intervir na complexidade de um objeto natural para retirar e quantificar seus constituintes. Assim, o conhecimento científico caminha inevitavelmente para a experimentação e para a fabricação de objetos técnicos que se tornam seus fins (Pinsart, 2003, p. 190).

Entretanto, que tipo de aliança se mostrava entre ciência e técnica antes do século XIX? Qual o estatuto do objeto técnico? Para responder à questão, Jonas toma o ser humano como ponto de partida, procurando nele os traços da liberdade que se revelam nas grandes etapas evolutivas do ser vivo. O princípio de mediação se torna um dos guias que o ajudam em sua leitura fenomenológica, uma vez que ele descreve o modo de ser e a evolução de todo organismo vivo. A primeira forma de mediação é o metabolismo, que é uma troca contínua de matéria do organismo com o meio exterior, em contraste com a substância inerte de Aristóteles, que se conhece através de sua imediaticidade a si. A atividade metabólica é, então, o primeiro nível de liberdade. Na evolução da ameba ao ser humano, as mediações variam em grau e essência. E um dos elementos que permitem entender a distância do homem em relação aos demais seres vivos é a ferramenta cujas tendências germinais já se encontram em alguns animais. $\mathrm{O}$ elemento propriamente humano é, para Jonas, a fabricação e a contemplação de imagens, pois a imagem permite ao homem se apropriar de um objeto de maneira não prática ${ }^{1}$. O mundo pode, então, ser objetivado na representação, não somente

\footnotetext{
${ }^{1}$ Guchet mostra como as nanotecnologias operam uma reviravolta nas análises de Jonas. "Fazer imagem de um nano-objeto significa, ao contrário,
} 
instrumentalizado, abrindo-se, assim, a possibilidade de que o homem se relacione com o mundo de dois modos: pela representação ou pela prática. A fabricação de uma ferramenta significa que o homem internalizou uma representação mental de uma ação possível sobre a matéria externa ou corporal, uma vez que a ferramenta se coloca entre o corpo (a mão) e o objeto e entre um objeto e um outro objeto quando ele é usado na fabricação de outras ferramentas. Para fabricar objetos, o ser humano modifica e faz associação com o ambiente. Uma ferramenta fabricada fica, então, à disposição para o uso, que é a finalidade para a qual ela foi criada. Embora o homem partilhe com os animais a capacidade de fabricar pequenas ferramentas, há uma diferença essencial: enquanto no animal os fins perseguidos são exclusivamente biológicos (beber, comer, etc.), no ser humano, aparecem outras finalidades e mediações. A ferramenta é para o homem o resultado da escolha de uma finalidade e a adequação de sua forma àquela, o que deixa um espaço grande para a imaginação. Uma boa ferramenta é aquela que cumpre bem a função para a qual foi fabricada, ou seja, aquela cuja forma é adequada ao seu fim

adquirir dados de manipulação sobre eles. A imagem conserva aqui o aspecto dinâmico que se acha esvaziado na percepção no sentido corrente do termo", como Jonas o entende. "Fazer imagem de um nano-objeto não quer dizer construir uma representação estática de um objeto", mas "uma ação sobre um nano-objeto, uma manipulação dinâmica que opera por meio de um microscópio em campo próximo" (Guchet, 2014, p. 91). As nanotecnologias nos colocam diante de uma situação inédita em relação ao que Jonas visualizou: "Fazer imagem de um nano-objeto não é fornecer uma representação cortada das forças que se exercem, mas, ao contrário, fornecer dados quantitativos que dizem respeito a essas forças" (Guchet, 2014, p. 92). Para ele, Jonas visualizou, para além das ameaças à vida, "aspectos interessantes ligados aos desenvolvimentos de novos modos de confrontação à matéria - transformação na maneira de se relacionar perceptivamente ao real, de construir conhecimentos", intuições que ele não desenvolveu. Jonas descartou ainda da técnica moderna a realidade de que ela "continua a manifestar a capacidade humana de inventar novos modos de confrontação à matéria, novas maneiras de se fabricar territórios e de perceber o mundo", continuando a aventura da vida em toda sua ambivalência. Guchet mostra ainda alguns domínios que permitiriam superar a visão jonasiana de técnica como sobrevivência, como os da etologia e os da paleoantropologia, embora ele não se ocupe de etologia. No domínio da paleoantropologia, a técnica deixa de ser um meio de sobrevivência para se tornar "um fato biológico com uma significação maior no processo pelo qual a vida se faz ida humana". Jonas aborda a técnica como própria do homem, deixando de considerar as técnicas animais. É a “técnica que nos instala na humanidade!” (Guchet, 2014, p. 92-3). Em Évolution et Liberté, Jonas afirma que "nenhum animal enterra seus mortos nem continua a lhes dedicar atenção, o que para Guchet é inexato. No texto Outil, image et tombeau: Du transanimal dans l'humain, Jonas, afirma Guchet, aborda questões de paleoantropologia, procurando o que há no homem de essencialmente transanimal. Nesse texto, Jonas nomeia as três características distintivas do homem e ausentes no animal, quais sejam, a fabricação de ferramentas, a capacidade de fazer imagens e de enterrar seus mortos. Enquanto a ferramenta introduz no homem uma diferença de grau em relação ao animal, a imagem e a sepultura introduzem uma diferença de essência. A fabricação de ferramentas depende da capacidade humana de imaginar e de formar imagens. Embora presente no animal e mais precisamente na vida como sobrevivência, a ferramenta abre ao homem o transanimal pela concepção de vida humana como capacidade de invenção antes que de sobrevivência e de conservação. A diferença humana se produz como a capacidade de fazer imagens (Jonas evoca os desenhos rupestres) e com a sepultura dos mortos. Guchet mostra que a capacidade de fazer imagens em pinturas se encontra, segundo as descobertas da paleoantropologia, sobretudo em partes da França e da Espanha, não se encontrando frequentemente em outras partes do mundo. Pergunta-se, então, se seriam, nesse caso, todas as espécies humanas que se sucederam ao homo habilis, há 10,5 milhões de anos, e que não deixaram registros de atividade técnica, desmerecedoras da denominação humana. Ele alega que o Homo neanderthalensis é faber, conhece a sepultura, mas não é pictor. Guchet se pergunta, então, se seria necessário inverter o processo jonasiano que conduz da ferramenta à sepultura, passando pela imagem, em um processo que vai da ferramenta à imagem, passando pela sepultura. Guchet mostra que a paleoantropologia contemporânea abandonou uma visão linear e progressiva por uma visão de "diversidade de espécies humanas, de formas de humanidade que povoaram a terra e de testemunhos lacunares de sua vida material, social e mental”. Quanto à sepultura como prova do transanimal e de uma vida voltada para o cultivo do espírito, pesquisas recentes confirmam que, embora possamos ter acesso aos ritos funerários e às crenças do Paleolítico que testemunham um período metafísico por excelência, não temos, no entanto, acesso aos conteúdos de suas representações, ou seja, temos acesso à sintaxe, mas não às significações. Guchet cita dois grandes nomes da paleoantropologia dos anos 1970 (Alsbert e Leroi-Gourhan) que concordam que o motor da evolução não foi a inteligência ou o espírito, mas a capacidade de fazer artefatos exteriores ao organismo. Jonas permanece silencioso sobre essas descobertas científicas já conhecidas em sua época. 
(Pinsart, 2003, p. 191-2).

A ferramenta permite a Jonas estabelecer uma diferença gradual entre o ser humano e o animal no plano da evolução natural. Até o século XIX, a ferramenta era um mero instrumento teórico e não prático, um meio a serviço do conhecimento, sem poder interferir no mundo físico. $\mathrm{O}$ artefato garantia uma melhor compreensão da natureza e a ciência deveria então melhorá-lo, além de inventar novos instrumentos. A natureza do saber científico era descritiva, classificadora e histórica. Com a Revolução Industrial, ciência e técnica se ligam indissoluvelmente, pois se fez necessário atender às necessidades crescentes e cada vez mais sofisticadas das necessidades humanas, inclusive na produção de forças necessárias ao funcionamento das máquinas. Aparecem, então, as máquinas como novas modalidades de objeto técnico que alteram as condições de trabalho. Com o aparecimento da indústria química e eletromagnética, torna-se possível uma intervenção profunda na natureza, com a indústria química modificando as substâncias e sintetizando novas. Não há mais espaço para imitar a natureza como no modelo platônico, mas procura-se a criação de algo inteiramente novo, impondo a ela profundas modificações e permitindo o estabelecimento de um novo modo de vida. A técnica se torna mais forte que a própria política, delimitando doravante o destino humano ${ }^{2}$.

Uma fase mais recente da evolução da técnica é representada pela biologia molecular. Tendo já modificado e recriado a matéria inanimada, o ser humano pode agora intervir no ser vivo a partir da extensão do modelo epistemológico da ciência física a todos os tipos de conhecimento, da rejeição de uma essência definida para a natureza humana e da liberdade de ação adquirida em todos os níveis da ação humana. Tais intervenções ameaçam tanto a vida humana como a não humana. Jonas se impõe, então, a tarefa de construir uma macro-ética, uma ética coletiva capaz de dar contas do futuro distante do planeta e das gerações futuras. Propõe, então, uma ética da responsabilidade coletiva.

O que chama a atenção na ética jonasiana é o enfoque dado às ameaças tanto à natureza humana quanto à natureza não humana, a tal ponto de ele colocar a continuidade da existência humana como o fim primeiro da ação política num paralelo que

\footnotetext{
${ }^{2}$ Uma avaliação crítica da técnica tal como ela é compreendida por Jonas é feita pelo filósofo francês da técnica, Xavier Guchet. Ele contesta o fato de somente a tecnologia moderna parecer a Jonas problemática, enquanto as técnicas antigas (ferramentas) não parecem apresentar nenhum problema. Para ele, "toda técnica tem uma relação externa à vida e a inquieta e essa inquietude se desdobra no seio mesmo da vida, é a vida mesma que é autonegação - a técnica é uma alteração da vida de dentro mesmo da vida (...). Com efeito, a vida é constitutivamente inquietude, provação do perigo e da morte". Guchet retoma as análises do Princípio Vida referentes ao metabolismo, a partir do conceito de mediação. Nessa obra, Jonas ensina que o vegetal é o ser vivo perfeito como "encarnação mais pura da essência da vida como relação do ser vivo àquilo que não é ele mesmo". A planta "tira do meio (milieu) as substâncias inorgânicas das quais ela tem necessidade para fabricar o orgânico", enquanto o animal não pode fabricar diretamente o orgânico a partir do mineral, tendo de assimilar outros seres vivos para sobreviver. Introduz-se, então, uma distância "entre o animal e seu meio e isto o obriga a se tornar um ser de mediações, um ser vivo condenado ao desvio". A técnica é, enquanto mediação, um novo meio a serviço do desvio, manifestando uma falta na vida que, no entanto, abre perspectivas novas ao ser vivo. Nas palavras de Guchet, a técnica é a forma humana dessa inquietude, dessa experiência da finitude e da morte, no seio mesmo de uma vida transanimal, mas sempre voltada ao desvio e à mediação. "O homem é o ser vivo no qual essa autonegação da vida acede à consciência de si" e a técnica tem aí um papel decisivo. Guchet vê uma dificuldade nesse ponto do pensamento de Jonas: em sua ontologia da morte, a vida é rebaixada à condição de sobrevida, ou seja, ela é definida como "aquilo que deve constantemente lutar contra as forças da morte a fim de se preservar e de se perpetuar". Em outras palavras, vida é reduzida a autonegação. Jonas passa, então, da vida como "prova da finitude e da morte no trabalho da mediação à vida como conjunto de forças que resistem à morte". Rebaixada à condição de sobrevida, a vida é falta em sua essência mesma.
} 
ele estabelece entre a responsabilidade parental e a responsabilidade política. $\mathrm{O}$ homem se distingue do animal pela ética ou, mais precisamente, pela capacidade de transcendência, e é pela responsabilidade que ele se mostra transcendente ao se descobrir como responsável não somente por si, mas por toda forma de existência. Sendo a fonte de toda a normatividade possível, não há valores sem o homem. Daí que a heurística do medo, que consiste num tipo de princípio de precaução, convide a agir de forma preventiva diante da presunção de catástrofes naturais causadas pelas novas tecnologias. Não se trata de frear o progresso, nem de renunciar à tecnologia e seus benefícios, mas de usá-los com responsabilidade, cientes do direito das futuras gerações à existência. Jonas preconiza também uma nova ciência que dê contas da interdependência entre todos os níveis de vida. Para lá de uma aparente tecnofobia, Jonas não deixa de ressaltar a capacidade de inventividade que a técnica permite ao homem, nem seu valor no alívio do sofrimento e na cura de doenças graves que as biotecnologias proporcionam. Se ela preenche uma falta na vida humana, é indissociável da vida, sendo ela mesma uma extensão da vida. Se a técnica aumenta a potên cia humana, aumenta também a capacidade humana de responsabilidade. Entre a reflexão e a ação, há um tempo que permite medir as consequências e os efeitos. O que não se pode nunca perder de vista é a continuidade da vida e esse deve ser também o objetivo primeiro da técnica.

\section{2. Ética e técnica em Levinas}

Levinas, por sua vez, examina a questão da técnica por um outro viés, trazendo-a para o terreno da ética, que é para ele a filosofia primeira. Passaremos por alguns de seus textos em que a questão vem à tona, sob diferentes perspectivas. Levinas pode ser considerado tecnófilo quando comparado a Heidegger e a Jonas, embora veja também uma ambiguidade na tecnologia.

Comecemos pela crítica à técnica para depois expor seu otimismo quanto àquilo que a tecnologia contemporânea proporciona ao homem. Em Le Moi et la Totalité, ele critica o movimento de totalização que o mundo tecnológico deixa ver. A técnica, associada à ciência matemática, opera um saber universal de uma razão impessoal portadora de um poder de neutralização que condena os ho-

\footnotetext{
E a técnica, nessa perspectiva da sobrevivência, é "um conjunto de meios em vista da satisfação das necessidades”, perspectiva antropológica e instrumentalista na qual não se enquadra mais a tecnologia moderna, e essa perspectiva é o que justifica a visão jonasiana da técnica como "força estrangeira à vida mesma". Isso, diz Guchet, desqualifica a técnica ao mesmo tempo em que desqualifica a vida humana, reduzida à condição de sobrevivência. A essência da vida não é a sobrevivência, mas uma "relação àquilo que não é ela mesma, uma relação ininterrupta ao não si, uma exteriorização continuada", sendo o metabolismo a "manifestação universal disso", já que todo metabolismo é já abertura ao mundo. Mas a técnica, se pergunta Guchet, não contraria essa caracterização universal do metabolismo? Para Jonas, "o metabolismo traz efetivamente a dimensão de exterioridade ao ser vivo, mas se trata de uma exterioridade que define a vida em sua essência, uma exterioridade que opera por consequência de dentro da vida", enquanto a técnica traz uma dimensão de exterioridade diferente: não "exterioridade da vida e na vida, mas exterioridade em relação à vida", de fora da vida que se impõe a ela como estranha ao seu movimento próprio. A técnica é coadjuvante, mediação através da qual alguns seres vivos satisfazem suas necessidades vitais e é nessa condição de algo externo à vida que a técnica ameaça essa mesma vida. Para Guchet, Jonas tenta encontrar um novo conceito de vida que não seja a mera sobrevivência a partir dos conceitos de metabolismo e de mediação, mas ele acha que Jonas não reavaliou simetricamente o conceito de técnica. Para Guchet, a apreciação jonasiana a respeito da tecnologia moderna se apoia sobre uma filosofia da vida que não é mais rebaixada à sobrevivência, o que lhe permite encontrar valores intrínsecos na vida, mas o conceito de técnica permaneceu sem modificação. Diz Guchet: se a tecnologia moderna pode se voltar brutalmente contra a vida (já que ela é sempre exterior à vida), isso significa que o conceito de técnica já foi excluído do conceito de vida.
} 
mens ao anonimato, impedindo-os de se verem no face a face. É a técnica que uniformiza as relações pessoais, dando-lhes contornos totalitários, uma vez que os indivíduos não se perdem apenas no todo anônimo e impessoal do Estado (alienação política), mas também a economia opera uma desindividualização do indivíduo. Afirma Levinas, em diferentes textos e ocasiões:

As transformações econômicas do mundo, a constituição de uma sociedade industrial internacional, aparecem aos mais espiritualistas dentre nós, como engendrando, por elas mesmas, uma humanidade vivendo no Universal (Levinas, 1994a, p. 146).

Em Liberté et Commandement, ele adverte que "um estado homogeneizado não é mais que o coroamento da sociedade industrial" (Levinas, 1994b, p. 75) e, em Entre Nous, afirma que "a injustiça pela qual o eu vive numa totalidade é sempre econômica" (Levinas, 1991, p. 40).

Portanto, a totalização econômica realiza uma corrupção do indivíduo, obrigando a interioridade do sujeito a se imiscuir no meio da exterioridade para aí submetê-lo ao objeto. Levinas reconhece assim a possibilidade de uma economia imoral que corrompe a interioridade por completo. E o princípio dessa imoralidade é o "anonimato do dinheiro", que é puro poder de objetivação e universalização que destrói a identidade e apaga o Rosto (Levinas, 1971, p. 151). As coisas não têm Rosto porque podem ser convertidas em dinheiro e têm apenas um preço. $\mathrm{O}$ intercâmbio econômico impõe o anonimato e impede o face a face. A vontade do trabalhador presente no produto se ausenta logo que ela se torna mercadoria (Levinas, 1994b, p. 44). Todos, assim, acabam se submetendo às forças impessoais do mercado, a outra forma cruel do imperialismo ontológico. Dessa maneira, certos modos de produção e certas formas de organização da economia impedem a relação ética, uma vez que tornam impossível o processo de singularização dos sujeitos e a proximidade do face a face. Se, num primeiro momento, a economia em Levinas é aquilo que torna possível a abertura ao Infinito, é ela também que produz a totalidade. Essa relação econômica primordial permite abrir um domínio diferente do da ontologia. Ao retirar as coisas do elemental, o trabalho as transforma em substâncias duráveis, mas suspende logo a independência de seu ser durável ao adquiri-las como bens móveis, transportáveis, colocados em reserva, depositados na morada (Levinas, 1971, p. 135). É a atividade econômica de produção que institui a substância como presença constante que então ganha independência do sujeito que a produziu. Assim, a produção industrial permite um distanciamento cada vez maior entre o produtor e o seu produto, preparando sua degradação até o nível de mercadorias e sua generalização através do dinheiro, raiz primeira da “alienação ontológica", a primeira injustiça que é a responsável pela instituição tanto da história como da totalidade (Levinas, 1991, p. 38-39).

Vê-se, assim, a denúncia que Levinas faz, reagindo à ontologia heideggeriana desde Totalidade e Infinito, em que ele reconhece a oposição de Heidegger à paixão técnica gerada pelo "esquecimento do ser escondido pelo ente", mas lamenta que sua ontologia tenha "levado fatalmente a um outro poder, à dominação imperialista, à tirania", que, aliás, "não é uma extensão pura e simples da técnica a homens reificados" (Levinas, 1971, p. 34). Autrement qu'être levará adiante, de forma mais radical, o projeto de superação da ontologia pela 
via da ética, buscando um eu fora da comunidade, do gênero e da forma que não encontra vantagem no repouso em si e não coincide consigo mesmo, uma unicidade sem lugar, de um eu que não coincide com o si, de uma unicidade se retirando da essência (Levinas, 1974, p. 20 et seq.). É nesse esforço constante de superação da ontologia que se deve entender a posição levinasiana acerca da técnica.

Embora Heidegger tenha se oposto à matematização da natureza, Levinas o critica também por ter cedido à inteligibilidade matemática, "comprimindo na ideologia o sujeito, a pessoa, sua unicidade e sua eleição; pelo enraizamento do homem no ser do qual ele seria o mensageiro e o poeta" (Levinas, 1972, p.101). Já numa de suas primeiras obras, De l'existence à l'existant, Levinas se opunha à caracterização da existência como ser-no-mundo, pois "a relação com um mundo não é sinônimo da existência. Esta é anterior ao mundo" (Levinas, 1998, p. 26). Nossa relação primeira ao ser escapa à relação com o mundo e assim escapa à inteligibilidade. A experiência da preguiça mostra certo recuo diante da existência, mostrando que o homem não está já de uma vez apegado a ela. "O fato de existir comporta então uma relação pela qual o existente faz contrato com a existência” (Levinas, 1998, p. 26). Com isso, a subjetividade se produz como o fato mesmo do começar que Levinas denomina hipóstase para se diferenciar da concepção heideggeriana da existência como êxtase que é "o próprio evento da existência" que faz a existência "contemporânea do mundo e da luz” (Levinas, 1998, p. 139).

Mas passemos à questão da técnica e da abordagem que dela faz Levinas no ensaio Heidegger, Gagarine et nous, publicado em 1961. Levinas aí aborda a questão da técnica, distinguindo-se da abordagem heideggeriana, que lhe parece demasia- do centrada em torno da questão do enraizamento ao solo, que, aos seus olhos, soa como uma visão contaminada pelo paganismo rural. Levinas situa a técnica na paisagem urbana. À primeira vista, nota-se a resistência levinasiana à questão do espaço. No ensaio Construir, habitar, pensar... (Heidegger, 2002, p. 125 et seq.), Heidegger insiste na noção de espaço e sua conexão com o ser do homem, dizendo que "os espaços recebem sua essência dos lugares e não do espaço" (Levinas, 1998, p. 134), ao que Levinas se opõe, dizendo que o sentido de espaço "refere-se à coexistência, à conjunção de todos os pontos, ao estar juntos com todos os pontos sem qualquer privilégio" (Levinas, 1974, p. 130). Sua filosofia prima pela responsabilidade para com o outro e pela justiça do face a face, que não dependem de um espaço em que elas se enraízem. São os arranjos sociais que criam os espaços.

A ressalva que Levinas faz à técnica se refere ao seu aspecto ideológico, quando ela se coloca a serviço de ideologias (caso do nazismo) ou se reveste de um culto pagão à natureza. Fora desses dois aspectos, ele a vê de modo bastante positivo, podendo contribuir para maior justiça social e para o diálogo entre as pessoas, criticando fortemente aqueles que veem a sociedade industrial de maneira demasiado pessimista.

Levinas se mostra convencido de que a humanidade do homem consiste num distanciamento em relação à natureza, pois "o homem habitaria a terra mais radicalmente que a planta que dela tira somente o suco nutridor" (Levinas, 1976, p. 325). O que distingue o estrangeiro do autóctone não é o enraizamento num lugar sem o qual o universo se torna sem sentido, chegando ele mesmo a dizer que a técnica é menos perigosa do que "os gênios do lugar". Para ele, "a técnica suprime o privilégio 
deste enraizamento e do exílio que aí se refere", quando ela não é compreendida no contexto pagão de ligação com a natureza. "Ela liberta desta alternativa” (Levinas, 1976, p. 325). A técnica permite "perceber os homens fora do contexto em que eles estão estabelecidos, deixa o rosto humano brilhar em sua nudez" (Levinas, 1976, p. 325). Levinas lembra Sócrates que preferia a cidade onde se encontram os homens ao campo e às árvores. Lugar ou espaço não são condições originais da experiência humana.

Ao mesmo tempo, Levinas saúda Gagarin, o primeiro russo a ir ao espaço, pela abertura que tal fato significa aos novos conhecimentos e às novas possibilidades técnicas que a ciência tornou possível. Acima de tudo, Levinas vê em Gagarin o fato de alguém ter deixado o "lugar", existindo por uma hora fora de todo horizonte: "Um homem existia no absoluto do espaço homogêneo" (Levinas, 1976, p. 326). Com isso, Levinas critica arduamente o apego ao solo e a identificação com a terra, quando eles são o único ponto a partir do qual nos relacionamos com outros pertencentes à mesma terra. Ele rejeita qualquer sentimento nostálgico com relação a um passado em que o mundo rural era predominante sobre o urbano, convocando o homem contemporâneo a não fugir às responsabilidades sociais que a civilização urbano-tecnológica lhe impôs.

A permanência do homem num mundo é apenas temporária, bem como a morada do corpo também é passageira. Ter um corpo, habitar um mundo não significa enraizamento num lugar específico, mas sim aí trabalhar, habitar, usufruir dos elementos do mundo e construir uma morada, um em-si onde se possa acolher outrem. Por isso, transformar tudo num espaço familiar de tal modo que o mistério se converta em significado, suprindo todas as necessidades, é, para nosso autor, eliminar a diferença e transformar o Outro no Mesmo. A fruição descrita por Levinas em Totalidade e Infinito, como o primeiro momento de constituição da subjetividade, é um estado infantil de felicidade anterior à reflexão que é interrompido pela vinda do outro que me convoca à responsabilidade. $\mathrm{O}$ mundo conserva um mistério que resiste à compreensão, impedindo a autossuficiência humana. Embora o corpo habite o mundo, ele se retira dele pela senescência. O ser-no-mundo seria ainda uma atitude natural que submete todas as coisas à mão, ao passo que a atitude ética consiste em dar do meu mundo ao outro (Levinas, 1971, p. 229). A pretensão heideggeriana de atingir o mistério do ser se mostra a serviço de um domínio total e irrestrito do mundo. Viver somente para si, preocupado em se preservar ou em sobreviver no ser, é ficar somente no nível da animalidade. A existência ética consiste em sair de si, preocupar-se com a morte do outro, em salvá-lo da morte, em desinteressar-se de si por causa do Outro. Diz Levinas:

\begin{abstract}
A relação a outrem no sacrifício, em que a morte do outro preocupa o ser-aí humano antes que a sua própria, não está a indicar, precisamente, um além da ontologia - ou um antes da ontologia - ao mesmo tempo determinando - ou revelando - uma responsabilidade pelo outro e, através dela, um "eu" humano que não é a identidade substancial de um sujeito nem a Eigentlichkeit na "minheidade" do ser (Levinas, 1991, p. 214).
\end{abstract}

A ética vem justamente interromper a fruição egoísta em nome de um altruísmo e de uma responsabilidade que se impõem ao eu, exigindo que o eu dê do seu mundo ao outro. Uma existência egoísta, definida essencialmente como esforço de 
autopreservação e de autoconservação, alimentadoras de competitividade cada vez mais acentuada entre seres humanos e suas sociedades, está por trás de uma economia industrial que vê a natureza exclusivamente como fonte de recursos a serem explorados e utilizados para nossa própria satisfação, não reconhecendo nela nenhum outro valor para além do valor de uso, impedindo-nos de vê-la a partir de uma dignidade moral que lhe seja inerente.

Em Hors Sujet, Levinas se mostra muito otimista quanto ao uso das ciências e das tecnologias a serviço do homem e de sua emancipação, não se notando em seu pensamento certo temor como aquele que se vê em Jonas em relação à técnica ou mesmo uma abordagem que ressalte mais seus efeitos negativos. Afirma ele que a ciência e as possibilidades da técnica permitem o respeito pelos direitos do homem, assim como o desenvolvimento das técnicas permitiu à humanidade europeia alcançar sua modernidade no centro da qual está o pensamento dos direitos do homem (Levinas, 1987, p. 162-3).

Assim, a tecnologia não se apresenta aos olhos de Levinas como má em si mesma, nem mesmo como um fim em si mesma, mas como um meio para alcançar a paz e a justiça entre os homens, desde que seja canalizada para a consecução destes fins. Com isso, a denúncia de Levinas contra a tecnologia se limita ao aspecto que a vê a serviço do "paganismo", que para ele se mostra igualmente pernicioso. Ela seria, então, "destruidora dos deuses pagãos e de sua falsa e cruel transcendência" que são os "deuses do orgulho e da dominação, deuses da conjunção astrológica e do fatum..." É a "técnica que os despoja de sua divindade" e nos "ensina que estes deuses são do mundo" (Levinas, 1991, p. 80-81).
O ateísmo em Levinas se coloca como uma possibilidade do ser separado e significa um fechamento em si na dependência do mundo e ainda um permanecer delimitado por seu horizonte, negando a verdadeira transcendência. Neste sentido, a tecnologia a serviço da desmistificação do mundo e das coisas pode estimular a verdadeira religião, libertando o sujeito do espaço que o prende à imanência do mundo e o fecha à transcendência. A técnica permitiria uma saída do em-si em que o mundo é visto apenas como aquilo que preenche minhas necessidades imediatas, de um mero nutrir-me dos elementos do mundo para uma existência em vista de outrem em que eu sou convocado a dividir com ele meu mundo, dando-lhe a comer do pão que eu conquistei, por meu trabalho, como parte do mundo a que eu julgo ter direito. E a técnica tem um papel fundamental nessa passagem da imanência do mundo à transcendência, uma vez que permite habitar o 'não-lugar' ou permite uma habitação sem enraizamento. A técnica propicia a abertura ao universal, libertando o homem de todo particularismo; ela permite, ainda, visualizar o humano, para além da natureza, na nudez de seu rosto.

O Rosto, significação em si mesma, é diferente das coisas que são situadas por Levinas no nível da fruição como objetos sem identidade em si mesmos. Por não terem um significado em si mesmas, as coisas podem ser convertidas em dinheiro. Com isso, as coisas não escapam ao horizonte do mundo. No mundo da tecnologia, o homem perdeu sua identidade, já que de agora em diante "existir equivale a explorar a natureza" e assim os "homens teriam perdido o mundo". Os homens agora só conheceriam a matéria vestida diante deles, objetivada, isto é, eles não conhecem nada mais que objetos. 
O Rosto é a possibilidade de se conhecerem os homens fora do lugar e fora de um 'enraizamento' ou, ainda, fora de um contexto ou de um mundo de tal modo que o Rosto possa brilhar em sua nudez (Levinas, 1976, p. 323 et seq.). Levinas situa o humano fora da natureza, fora da ordem natural das coisas, pois, na relação com outrem, ele está em relação com Deus. É a partir dessa relação que o mundo se torna inteligível e não a partir de lugares, templos, casas (Levinas, 1976, p. 325). Outrem não pertence ao mundo, nem vem do mundo, mas é exterioridade absoluta. Assim, ao permitir que o homem se retire da fascinação pelas coisas (o que, para Levinas, é idolatria!), a técnica dá o primeiro passo para que ele encontre outrem.

\section{Aproximações entre Jonas e Levinas: a responsabilidade como elemento comum}

Os dois projetos filosóficos tomaram direções praticamente opostas, tendo Jonas fundado a ética numa ontologia, exigência dispensável aos olhos de Levinas, que a pensa justamente como a filosofia primeira, não sendo necessária uma ontologia que a prepare. No entanto, qual seria o elemento que aproxima dois projetos filosóficos tão díspares nas direções que tomaram para propor uma ética? Sem dúvida, a ética jonasiana é uma ética da responsabilidade e, da parte de Levinas, a responsabilidade é um elemento fundamental constitutivo da subjetividade ética. Assim, a responsabilidade aparece como um elemento imprescindível para pensar a ética em ambos os pensadores. Se, para Jonas, a responsabilidade tem, então, uma dimensão ontológica, para Levinas ela exige uma ruptura com a ontologia. A ética da responsabilidade em Jonas tem por objetivo último, ou como valor máximo e absoluto, a continuidade da humanidade (por que o ser antes que o nada?), ao passo que a ética de Levinas, desviando-se da questão do ser, se volta para a justificação do ser (como o ser se justifica?).

Em ambos, o cuidado pelo outro é central e constitutivo da noção de responsabilidade, seja o cuidado para com a continuidade da existência nas gerações futuras (Jonas), seja o cuidado pelo outro (Levinas). Em ambos, trata-se de uma responsabilidade gratuita ou desinteressada que não exige reciprocidade como sua condição. Levinas fala de uma responsabilidade assimétrica para mostrar a prioridade do outro em relação ao eu, e Jonas, por sua vez, compara a responsabilidade do homem político encarregado de deixar um mundo viável para as próximas gerações à responsabilidade parental de cujos cuidados depende a sobrevivência do recém-nascido. Não se trata de uma responsabilidade jurídica, mas de uma responsabilidade ética. Ao contrário de Kant, que propõe uma ética da autonomia, vemo-nos aqui diante de duas éticas heterônomas, uma vez que a exigência moral procede de uma alteridade. É do encontro com o Rosto - que não é o rosto físico, mas um comando moral que foge a toda forma de objetivação ou de identificação racional - que vem o imperativo ético: "Não matarás!". O Rosto, em Levinas, é o lugar mesmo do sentido. Nem se trata, ainda, por outro lado, de ver aí a compaixão ou mesmo a simpatia ou o respeito como formas de identificação com o outro, pois ambas ameaçam arrancar a outrem a prioridade e a autonomia absolutas que lhe são conferidas. Outrem me arranca do fechamento em mim mesmo, da indiferença à morte e ao seu sofrimento. Também da parte de Jonas, nota-se um movimento semelhante na responsabilidade do ho- 
mem político que não visa a seu próprio interesse, mas se acha investido de um poder que se exerce sobre a totalidade da existência humana tomada em seu futuro e continuidade. Nos dois casos, trata-se de uma responsabilidade pelo vulnerável ou pelo frágil que simplesmente pode morrer ou deixar de existir se aquele que tem poder sobre ele abandonar a vigilância. $O$ recém-nascido apela ao poder dos pais, de quem depende sua sobrevivência, e outrem apela a mim a partir de sua condição frágil e vulnerável. O dever ser que se impõe no apelo, seja de outrem, seja do recém-nascido, convoca o sujeito ético a uma responsabilidade que não é escolhida por ele e que, no entanto, exige dele uma resposta.

No caso de Jonas, é a técnica e a tecnologia que ameaçam a continuidade da humanidade e isso explica o fim último de sua ética da responsabilidade: a preservação da humanidade. Nosso cuidado - outro elemento fundamental de ambas as éticas - nos obriga, então, a dar prioridade ao humano e não meramente ao si mesmo. A ameaça de extinção da humanidade arranca o sujeito ético da fruição egoísta de si mesmo e do mundo, acordando-o para uma responsabilidade maior que ele mesmo, que é a responsabilidade pela continuidade da humanidade na existência. Da parte de Levinas, a angústia pela sorte do outro ou por sua morte tem prioridade sobre a preocupação ou sobre a angústia com a minha própria morte, que, em Heidegger, é constitutiva de minha autenticidade. Note-se que ambos os pensadores são herdeiros críticos de Heidegger. Em Jonas, são as gerações futuras que reclamam o direito de existir que se sobrepõem ao direito de ser si mesmo, sendo que a responsabilidade obriga a uma reconfiguração do si mesmo, que não é nada sem outrem, por quem ele é chamado à responsabilidade, afirmando-se o sujeito e sua identidade na resposta antes que a partir de si mesmo ou na responsabilidade por si. Levinas, por sua vez, vai ainda mais longe e usa o termo "refém do outro" para designar esse ato de ser tomado pelo outro na responsabilidade. Do mesmo modo, Jonas pensa que ascendo à condição de sujeito responsável quando sou desinstalado do esforço por minha própria autopreservação ou autoconservação em nome das necessidades, seja do recém-nascido, seja das gerações futuras que se acham igualmente em situação de vulnerabilidade e ameaçadas em sua existência. Em ambos, a existência de outrem ou sua continuidade na existência dependem de minha capacidade de responder ao seu apelo e à sua fragilidade. Em sua obra da maturidade filosófica Autrement qu'être ou au-délà de l'essence-, em que o filósofo franco-lituano propõe a substituição da linguagem ontológica pela linguagem ética, fala-se de 'substituição' de modo que minha humanização não encontra primeiramente na liberdade sua fonte, mas antes no serviço ao outro. Ainda que essa responsabilidade tenda sempre a outro ser humano, podemos alargá-la e abri-la a todos os seres vivos, como o exige uma ética ambiental. A noção levinasiana de Rosto precisa incluir, de alguma maneira, o animal e outros seres vivos. Afinal, é toda a natureza que me convoca à responsabilidade e ela não pode ser vista unicamente à maneira cartesiana que lhe conferiu o mero estatuto de res extensa (coisa). A ética ambiental mostra que formamos uma comunidade de vida com todos os demais seres vivos e que a vida é uma cadeia em que a extinção de uns implica ameaça ou mesmo extinção dos demais, não mais se justificando qualquer forma de antropocentrismo que vê a natureza unicamente como meio para os fins humanos.

Pommier, comentarista chileno de Jonas, diz 
haver no manuscrito original de $O$ Princípio Vida, conservado na Universidade de Constança, a ideia de que não é a minha morte o "horizonte de minha inquietude vital, mas aquela da minha primogenitura" (Pommier, 2013, p. 220). Logo, o sentido da vida consiste no devotamento ao outro e não meramente no cuidado de si, ideia central de toda a ética levinasiana. Vê-se, então, que a ética jonasiana - ainda que fundada numa ontologia contém uma abertura à alteridade, mesmo que essa abertura se dê a partir de si. No entanto, outrem, na concepção levinasiana, não vem do mundo e nada tem em comum com o eu. Como, então, uma ética sem mundo como a de Levinas pode ajudar a pensar a preservação da vida animal e a de todos os demais seres vivos? É nesse sentido que a noção de Rosto pode ser alargada para que se inclua aí a preocupação com todas as formas de vida além da propriamente humana. Todas as formas de alteridade convocam e apelam à responsabilidade do eu, exigindo dele uma resposta. Concluímos assim que, embora tão distintos, os dois projetos filosóficos se aproximam quando veem na responsabilidade o cerne da ética, e só a responsabilidade é capaz de se erigir em resposta à altura das questões que a ética ambiental nos coloca.

\section{Conclusão}

A visão jonasiana a respeito do homem é a de que ele é um ser do mundo, do cosmos, da natureza, do mesmo mundo dos objetos e das obras, e a técnica faz mesmo parte de sua constituição ontológica, já que ela é aquilo que o instala na humanidade. Não haveria homem sem técnica, pois ela é o diferencial que o distancia do animal não humano. Apesar de ser algo como que complementar ao ser humano, uma mediação, a técnica pode também comprometer a continuidade da própria existência humana. Apesar de construir sua ética sobre a ontologia, Jonas visualiza a capacidade humana de se colocar no lugar de outrem, principalmente quando convida a uma responsabilidade coletiva para com as gerações futuras cujo senso de responsabilidade impõe sobre nós os direitos também daqueles que ainda não existem, mas que têm direito a existir. A técnica se situa, então, dentro desse fim último que é a preservação e a continuidade da espécie humana, devendo a humanidade se precaver contra aquilo que ameaça sua própria essência. Jonas, a nosso ver, não chega a ser um tecnofóbico radical, pois é capaz de reconhecer os benefícios da técnica, seu papel essencial de mediação, mas alerta contra seu potencial crescente de extermínio, chegando a ameaçar a continuidade da existência humana e não humana. A marca característica da transcendência humana se vê em sua noção de responsabilidade, que, ainda que pensada a partir de si mesma, contém, no entanto, a nosso ver, uma abertura à alteridade das futuras gerações, pois não se trata meramente de uma responsabilidade por si mesmo, mas pelo outro.

Da parte de Levinas, o humano não pertence à ontologia, que, a seu ver, ainda permanece fechada à imanência do mundo, presa ao contexto, à preocupação do ser humano com sua própria conservação e autopreservação, características que o autor atribui à animalidade. Nesse sentido, a técnica é o elemento que leva para fora do fechamento em si mesmo e permite ver o humano para além do espaço e do lugar. Embora a economia e a tecnologia ameacem despersonalizar os seres humanos na obra da totalização apagadora da alteridade, elas, ainda assim, permitem visualizar o Rosto em toda sua nudez para além de qualquer contexto e cultura. Entendemos 
que a postura de Levinas vai mais na direção da tecnofilia, uma vez que o ser humano, com a ajuda da técnica, pode visualizar melhor o humano que não tem o lugar como sua condição e pode, assim, acolher outrem, habitando o mundo não como sua propriedade ou o lugar ao qual se tem direito, mas como o não lugar do qual outrem me desinstala, convidando-me a socorrê-lo em sua vulnerabilidade. A noção de Rosto como comando moral que convoca à responsabilidade pode incluir também

\section{Referências}

Guchet, X. L'homme, la technique et la vie dans la Philosophie de Hans Jonas. Une aproche critique. Alter - Revue de Phénoménologie, 22, 79-99, 2014.

Heidegger, M. Ensaios e conferências. Petrópolis: Vozes/ Universidade São Francisco, 2002.

Jonas, H. Essais Philosophiques. Du credo ancien à l'homme technologique. Paris: J. Vrin, 2013.

Levinas, E. Totalité et Infini. La Haye: Martinus Nijhoff, 1971.

Levinas, E. Humanisme de l'Autre Homme. Paris: Fata Morgana, 1972.

Levinas, E. Autrement qu'être ou au-délà de l'essence. La Haye: Martinus Nijhoff, 1974.

Levinas, E. Difficile Liberté. Paris: Albin Michel, 1976. os seres não humanos, que são também formas de alteridade que, por sua vulnerabilidade de seres que podem ser mortos, nos colocam em questão e suspendem nosso existir como mera perseverança em nosso ser. A responsabilidade pensada inicialmente pelo autor apenas como responsabilidade pelo outro homem pode e precisa incluir também a alteridade dos seres não humanos para contribuir, assim, para pensar uma nova ética ambiental.

Levinas, E. Hors Sujet. Paris: Fata Morgana, 1987.

Levinas, E. Entre-nous - Essais sur le Penser-a-l'autre. Paris: Grasset, 1991.

Levinas, E. Sécularisation et Faim. In: Cahiers de l'herne, no. $60,1991$.

Levinas, E. Les Imprévus de l'histoire. Paris: Fata Morgana, 1994a.

Levinas, E. Liberté et Commandement. Paris: Fata Morgana, 1994b.

Levinas, E. De l'existence à l'existant. Paris: Livrairie Philosophique J. Vrin, 1998.

Pinsart, M. G. Hans Jonas: une réflexion sur la civilisation technologique. In: Chabot, P. ; Hottois, G. (Eds.). Les philosophes et la technique. Paris: J. Vrin, 2003, p. 190.

Pommier, E. Ontologie de la vie et éthique de la responsabilité selon Hans Jonas. Paris: J. Vrin, 2013. 